\title{
Analisis Efek Moderasi Penerimaan Teknologi Komputasi Awan Pada Mahasiswa Jakarta Selatan
}

\author{
Anggar Riskinanto ${ }^{1)}$, Bayu Kelana ${ }^{2)}$ \\ Sistem Informasi, Sekolah Tinggi Ilmu Manajemen dan Ilmu Komputer ESQ \\ Menara 165 Lt. 18-19, Jakarta, 12560 \\ ${ }^{1)}$ Email: anggar.r@esqbs.ac.id, \\ ${ }^{2)}$ Email: bayu@esqbs.ac.id
}

\begin{abstract}
The use of the Internet has penetrated all aspects of life. One of them in the academic world, is used as a solution to share knowledge and collaborate. The use of cloud computing is one example that allows the academic community to do so. Based on the initial interview, cloud computing technology is only used as a document storage media. Therefore this study aims to examine the factors that influence the use of this technology. The research conducted is quantitative and uses purposive random sampling technique. The questionnaire was distributed in the form of paper and Google Form to S1 students majoring in information systems in South Jakarta and obtained as many as 297 respondents. Data processing was done using PLS-SEM, the result of which was that most hypotheses were accepted with the greatest influence on attittude constructs to continued use intention. But in the moderation effect test, all hypotheses are rejected. This means that the use of technology in students is influenced by their attitude. However, it makes no difference for men and women. The same is true for experienced or not students.
\end{abstract}

Keywords: cloud computing, PLS, students, technology acceptance

\begin{abstract}
Abstrak: Penggunaan Internet telah merambah ke segala aspek kehidupan. Salah satunya dalam dunia akademik, digunakan sebagai solusi untuk saling berbagi pengetahuan dan berkolaborasi. Penggunaan komputasi awan merupakan satu contoh yang memungkinkan sivitas akademika melakukan hal tersebut. Berdasar wawancara awal, teknologi komputasi awan hanya digunakan sebagai media penyimpanan dokumen. Karena itu penelitian ini bertujuan untuk meneliti faktor-faktor yang mempengaruhi penggunaan teknologi ini. Penelitian yang dilakukan bersifat kuantitatif dan menggunakan teknik purposive random sampling. Kuesioner disebar dalam bentuk kertas dan Google Form kepada para mahasiswa S1 jurusan sistem informasi di Jakarta Selatan dan didapatkan responden sebanyak 297. Pengolahan data dilakukan menggunakan PLS-SEM, yang hasilnya adalah sebagian besar hipotesis diterima dengan pengaruh terbesar pada konstruk attittude kepada continued use intention. Namun pada uji efek moderasi, semua hipotesis ditolak. Ini berarti bahwa penggunaan teknologi pada mahasiswa dipengaruhi oleh sikap mereka. Namun, tidak ada bedanya bagi pria maupun wanita. Hal yang sama juga untuk mahasiswa berpengalaman atau tidak.
\end{abstract}

Kata kunci: komputasi awan, mahasiswa, penerimaan teknologi, PLS

\section{PENDAHULUAN}

Internet dewasa ini telah masuk ke dalam kehidupan manusia sehari-hari. Penggunaan teknologi ini terlihat dari tidak hanya sekedar untuk kebutuhan berkomunikasi, tapi juga digunakan untuk menjadi sebuah bagian pentin dari kegiatan bisnis. Salah satu solusi Internet yang kian masif digunakan oleh orang banyak adalah layanan komputasi awan (cloud computing), dimana ia memungkinkan penggunanya untuk mengakses infrastruktur komputer di mana saja dan kapan saja, dengan menggunakan perangkat apa saja, asalkan terhubung pada jaringan Internet.
Salah satu penggunaan darikomputasi awanyang juga kiat meningkat adalah pada dunia pendidikan. Dengan kemudahan akses Internet, para dosen dan mahasiswa bisa saling bertukar data melalui layanan ini. Selain sebagai media penyimpanan, beberapa solusi (contohnya Dropbox atau Google) juga menawarkan fitur kolaborasi untuk saling berbagi pengetahuan. Fitur ini memungkinkan para pengguna saling berkolaborasi untuk menyelesaikan tugas dalam satu waktu, meski tidak dalam satu tempat. Namun berdasarkan wawancara awal, kebanyakan mahasiswa hanya menggunakan teknologi ini sebagai sarana penyimpanan dan pertukaran dokumen (cloud 
storage). Sehingga potensi yang ada pada komputasi awan tidak digunakan secara maksimal.

Atas fenomena ini, maka peneliti ingin melihat bagaimana penggunaan teknologi komputasi awan digunakan di kalangan mahasiswa. Berdasarkan pengamatan awal yang disebutkan sebelumnya, para mahasiswa memang sudah menggunakan teknologi ini sebagai bagian dari kegiatan kampus mereka. Maka peneliti ingin melihat secara dalam bagaimana penggunaan teknologi ini apabila dikaitkan dengan manajemen pengetahuan. Penelitian ini ditujukan untuk mengetahui faktor-faktor apa saja yang mempengaruhi penggunaan teknologi komputasi awan di kalangan mahasiswa.

\section{A. Manajemen Pengetahuan}

Manajemen pengetahuan bisa diartikan sebagai sebuah "keyakinan sejati yang benar", dimana ia akan meningkatkan kualitas individu atau kapasitas organisasi untuk mengambil tindakan efektif [1] Manajemen pengetahuan pada umumnya juga mengacu pada proses untuk mengidentifikasi dan memanfaatkan pengetahuan bersama dalam sebuah organisasi untuk membantu organisasi bersaing [2].

Dalam manajemen pengetahuan, terdapat sebuah hubungan sinergis antara dua tipe pengetahuan, yaitu tasit dan eksplisit. Hubungan sinergis pada dua pengetahuan ini digambarkan oleh Nonaka sebagai model SECI [3]. Model ini terdiri dari beberapa proses yaitu socialization, externalization, combination, dan internalization.

\section{B. Komputasi Awan}

Layanan penyimpanan awan merupakan bagian dari solusi komputasi awan (cloud computing) yang menawarkan sebuah kesatuan perangkat komputasi. Prinsip utama layanan ini adalah kemampuannya dalam menawarkan komputasi, penyimpanan, dan software sebagai satu layanan [4]. Karakteristik dari layanan ini antara lain adalah: pay-per-use (tanpa komitmen kelanjutan, biaya perangkat); kapasitas elastis dan ilusi akan sumber daya yang tak terbatas; antar-muka mandiri; dan sumber daya yang diabstraksi atau virtualisasi.

Umumnya, layanan cloud computing terbagi menjadi tiga tingkatan, yaitu Infrastructure as a service (IaaS), Platform as a service (PaaS), Software as a service (SaaS).

\section{Technology Acceptance Model}

TAM merupakan model yang paling banyak digunakan oleh peneliti untuk menjelaskan penerimaan sebuah teknologi pada pengguna. Pengukuran dilakukan dengan cara menguji tingkat persepsi penerimaan pengguna terhadap teknologi yang ia gunakan [1]. TAM pertama kali diperkenalkan oleh Davis [5] yang merupakan pengembangan dari teori penelitian Theory Reasoned Action (TRA) dan Theory of Planned Behavior(TPB). Karena merupakan pengembangan dari teori psikologi, maka model ini memungkinkan untuk menjelaskan mengenai kebiasaan dari sang pengguna. Dimana didasarkan pada konsep hubungan antara kepercayaan, sikap, keinginan, dan hubungan perilaku pengguna.

Pada TAM terdapat 5 konstruk yang digunakan untuk mengetahui penerimaan teknologi. Konstrukkonstruk ini adalah perceived ease of use, perceived usefulness, attitude towards using, behavior intention, dan actual use.

\section{METODE PENELITIAN}

\section{A. Model Penelitian}

Penelitian mengadopsi dari model penelitian yang telah dilakukan oleh Arpaci. Model ini digunakan untuk meneliti penggunaan teknologi awan pada mahasiswa di sebuah universitas bisnis di Turki pada 2017. Peneliti kemudian melakukan beberapa perubahan untuk menyesuaikan dengan keadaan para mahasiswa yang menjadi obyek penelitian. Detail dari model penelitian yang menjadi acuan dapat dilihat pada Gambar 1 berikut.

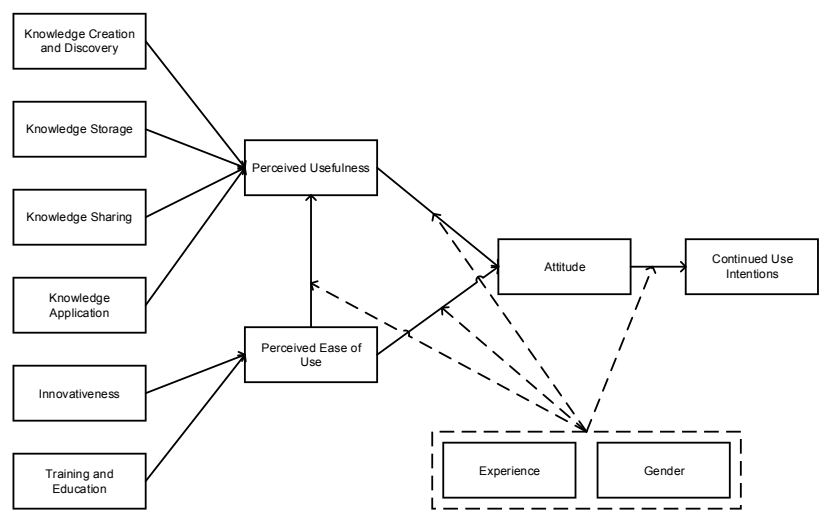

Gambar 1. Model Penelitian

\section{B. Hipotesis Penelitian}

Berdasar Gambar 1 maka bisa didapatkan beberapa hipotesis penelitian yang digunakan untuk menguji pengaruh antar konstruk. Hipotesis yang diajukan pada penelitian ini adalah:

H1: Attitudes berpengaruh secara positif dengan Continued Use Intentions yang dimoderasi oleh Experience dan Gender. 
$\mathrm{H} 2$ : Perceived Ease of Use berpengaruh secara positif dengan Attitudes yang dimoderasi oleh Experience dan Gender.

H3: Perceived Ease of Use berpengaruh secara positif dengan Perceived Usefulness yang dimoderasi oleh Experience dan Gender.

H4: Perceived Usefulness berpengaruh secara positif dengan Attitudes yang dimoderasi oleh Experience dan Gender.

H5: Knowledge Creation and Discovery berpengaruh secara positif terhadap Perceived Usefulness.

H6: Knowledge Storage berpengaruh secara positif terhadap Perceived Usefulness.

H7: Knowledge Sharing berpengaruh secara positif terhadap Perceived Usefulness.

H8: Knowledge Application berpengaruh secara positif terhadap Perceived Usefulness.

H9: Innovativeness berpengaruh secara positif dengan Perceived Ease of Use.

H10: Training and Education berpengaruh secara positif dengan Perceived Ease of Use.

\section{HASIL DAN PEMBAHASAN}

Penelitian yang dilakukan oleh peneliti bersifat kuantitatif karena pertimbangan jumlah responden dan sifat dari penelitian ini sendiri. Untuk mendapatkan respon dari para obyek penelitian, maka disebar kuesioner dalam bentuk kertas tercetak cetak dan melalui kanal online dalam bentuk Google Form. Jawaban pada kuesioner menggunakan skala Likert dengan interval 1 yang menunjukkan Sangat Tidak Setuju, hingga 4 yang menunjukkan Sangat Setuju. Dari kuesioner yang disebar di beberapa kampus di wilayah Jakarta Selatan, didapatkan sebanyak 297 responden. Responden yang menjadi obyek penelitian merupakan para mahasiswa jenjang S1 di jurusan Sistem Informasi.

Detail mengenai demografi para responden dapat dilihat pada Tabel 1 di bawah.

Tabel 1. Profil demografi responden

\begin{tabular}{cccc}
\hline Kategori & Variabel & \multicolumn{2}{c}{ FrekuensiPersentase } \\
\hline Jenis Kelamin & Pria & 183 & $62 \%$ \\
& Wanita & 114 & $38 \%$ \\
\hline Pengalaman Kurang 6 Bln & 82 & $28 \%$ \\
6 Bln - 1 Thn & 43 & $14 \%$ \\
1 - 3 Thn & 111 & $37 \%$ \\
4 Thn Lebih & 61 & $21 \%$ \\
\hline
\end{tabular}

Pada Tabel 1 terlihat bahwa persentase jumlah mahasiswa pria sekitar dua kalinya mahasiswa wanita. Sedangkan pengguna yang mempunyai pengalaman terbanyak adalah pada mahasiswa tahun kedua. Dimana yang terkecil adalah mahasiswa tahun pertama. Setelah didapatkan respon dari para mahasiswa, maka tahapan berikutnya adalah melakukan analisis terhadap model dan hipotesis penelitian. Untuk membantu peneliti dalam melakukan analisis, maka digunakan metode SEMPLS (Structural Equation Model-Partial Least Square). Metode ini menggunakan dua tahapan dalam analisisnya, yaitu analisis outer model dan analisis inner model. SmartPLS 2.M3 digunakan untuk membantu dalam tahapan ini.

\section{A. Analisis Outer Model}

Pada tahapan ini, peneliti menguji terhadap nilai-nilai indicator reliability, indicator consistency, convergent validity, dan discriminant validity. Semua analisis yang dilakukan bertujuan untuk menguji dari nilai validitas dan reliabilitas model penelitian. Berdasar dari pengujian yang telah dilakukan, maka didapatkan hasil berikut tertera pada Tabel 2 .

Pada Tabel 2 bisa terlihat bahwa uji indicator reliability telah memenuhi syarat, dimana nilai loading factor dari tiap indikator harus melebihi nilai 0,4 [6]. Sedangkan pada uji indicator consistency, bisa dilihat pada nilai composite reliability (CR). Dari uji yang dilakukan, ternyata semua konstruk telah memenuhi syarat, yaitu lebih besar dari 0,7 [6]. Kemudian pada uji convergent validity yang bisa diperlihatkan dari nilai average variance extracted (AVE), semua konstruk telah memenuhi nilai standar yaitu 0,5 [7].

Analisis terakhir pada fase ini dilakukan dengan menguji terhadap divergent validity. Uji yang dilakukan bisa dilihat pada Tabel 3 .

Pada uji yang diperlihatkan pada Tabel 3, nilai acuan pada tiap konstruk (cetak tebal dan miring) lebih besar dari nilai lainnya, sehingga bisa diambil kesimpulan sebagai memenuhi syarat validitas [8]. Dari semua uji yang dilakukan, bisa disimpulkan bahwa uji outer model telah terpenuhi validitas dan reliabilitasnya. Sehingga uji bisa dilakukan ke tahap berikutnya, yaitu analisis inner model.

\section{B. Analisis Inner Model}

Analisis ini digunakan untuk menguji hubungan dan pengaruh yang ada pada tiap-tiap konstruk pada model penelitian. Pengujian dilakukan dengan mengacu terhadap $t$-value pada semua hipotesis penelitian. Detail dari nilai-nilai ini diperlihatkan pada tabel-tabel di bawah. Hasil pengujian hipotesis yang telah diajukan bisa dilihat dari nilai $t$-value pada Tabel 4. 
Tabel 2. Analisis outer model

\begin{tabular}{|c|c|c|c|c|}
\hline Konstruk & Item & $\begin{array}{c}\text { Loading } \\
\text { factor }\end{array}$ & AVE & CR \\
\hline Knowledge & $\mathrm{KC1}$ & 0.675 & & \\
\hline Creation and & $\mathrm{KC} 2$ & 0.725 & 0.575 & 0.801 \\
\hline Discovery & $\mathrm{KC} 3$ & 0.862 & & \\
\hline \multirow{3}{*}{$\begin{array}{l}\text { Knowledge } \\
\text { Storage }\end{array}$} & KST1 & 0.854 & \multirow{3}{*}{0.739} & \multirow{3}{*}{0.895} \\
\hline & KST2 & 0.841 & & \\
\hline & KST3 & 0.883 & & \\
\hline \multirow{3}{*}{$\begin{array}{l}\text { Knowledge } \\
\text { Sharing }\end{array}$} & KSH1 & 0.799 & \multirow{3}{*}{0.638} & \multirow{3}{*}{0.841} \\
\hline & KSH2 & 0.753 & & \\
\hline & KSH3 & 0.841 & & \\
\hline \multirow{3}{*}{$\begin{array}{l}\text { Knowledge } \\
\text { Application }\end{array}$} & KA1 & 0.865 & \multirow{3}{*}{0.778} & \multirow{3}{*}{0.913} \\
\hline & KA2 & 0.897 & & \\
\hline & KA3 & 0.884 & & \\
\hline \multirow{4}{*}{ Innovativeness } & IN1 & 0.765 & \multirow{4}{*}{0.503} & \multirow{4}{*}{0.799} \\
\hline & $\mathrm{IN} 2$ & 0.695 & & \\
\hline & IN3 & 0.804 & & \\
\hline & IN4 & 0.545 & & \\
\hline \multirow{3}{*}{$\begin{array}{l}\text { Training and } \\
\text { Education }\end{array}$} & TE1 & 0.775 & \multirow{3}{*}{0.731} & \multirow{3}{*}{0.89} \\
\hline & TE2 & 0.895 & & \\
\hline & TE3 & 0.89 & & \\
\hline \multirow{3}{*}{$\begin{array}{l}\text { Perceived Ease } \\
\text { of Use }\end{array}$} & PEU1 & 0.903 & \multirow{3}{*}{0.831} & \multirow{3}{*}{0.936} \\
\hline & PEU2 & 0.922 & & \\
\hline & PEU3 & 0.909 & & \\
\hline \multirow{5}{*}{$\begin{array}{l}\text { Perceived } \\
\text { Usefulness }\end{array}$} & PU1 & 0.848 & \multirow{5}{*}{0.692} & \multirow{5}{*}{0.918} \\
\hline & PU2 & 0.829 & & \\
\hline & PU3 & 0.874 & & \\
\hline & PU4 & 0.833 & & \\
\hline & PU5 & 0.773 & & \\
\hline \multirow{3}{*}{ Attitude } & AT1 & 0.842 & \multirow{3}{*}{0.785} & \multirow{3}{*}{0.916} \\
\hline & AT2 & 0.917 & & \\
\hline & AT3 & 0.896 & & \\
\hline \multirow{3}{*}{$\begin{array}{l}\text { Continued Use } \\
\text { Intentions }\end{array}$} & IU1 & 0.891 & \multirow{3}{*}{0.795} & \multirow{3}{*}{0.921} \\
\hline & IU2 & 0.899 & & \\
\hline & IU3 & 0.884 & & \\
\hline
\end{tabular}

Tabel 3. Kriteria Fornell-Larcker

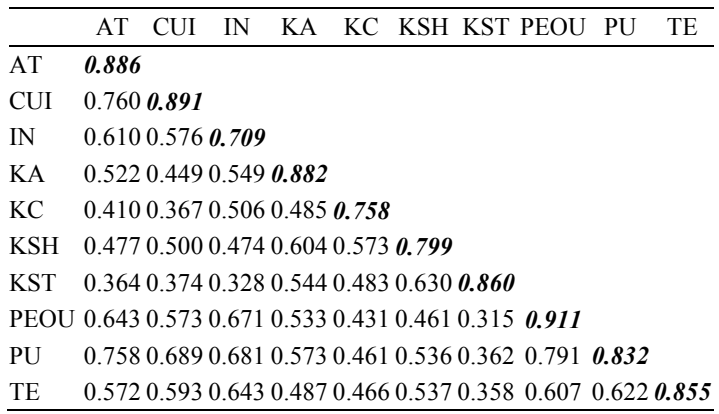

Pada Tabel 4 terlihat bahwa sebagian besar hipotesis diterima. Hanya 3 hubungan yang ditolak, yaitu pengaruh knowledge creation and discovery terhadap perceived usefulness, pengaruh knowledge storage terhadap perceived usefulness, dan pengaruh perceived ease of use terhadap attitude. Hipotesis dapat diterima atau tidak, ditentukan dari t-value yang melebihi nilai 1,96 [9]. Terlihat juga pada Tabel 4 bahwa pengaruh terkuat dari model penelitian ini adalah antara konstruk attittude dengan continued use intention dengan nilai $t$-value sebesar 22,389.
Tabel 4. Uji hipotesis

\begin{tabular}{cccc}
\hline Hipotesis & Hubungan & t-value & Keputusan \\
\hline H1 & AT $\rightarrow$ CUI & 22.389 & Diterima \\
H2 & PEOU $\rightarrow$ AT & 1.29 & Ditolak \\
H3 & PEOU $\rightarrow$ PU & 13.956 & Diterima \\
H4 & PU $\rightarrow$ AT & 8.461 & Diterima \\
H5 & KC $\rightarrow$ PU & 0.956 & Ditolak \\
H6 & KST $\rightarrow$ PU & 0.557 & Ditolak \\
H7 & KSH $\rightarrow$ PU & 2.569 & Diterima \\
H8 & KA $\rightarrow$ PU & 2.645 & Diterima \\
H9 & IN $\rightarrow$ PEOU & 7.264 & Diterima \\
H10 & TE $\rightarrow$ PEOU & 4.214 & Diterima \\
\hline
\end{tabular}

\section{Analisis Efek Moderasi}

Tahapan terakhir yang dilakukan dari penelitian ini adalah menguji terhadap dua konstruk moderasi yaitu, Jenis Kelamin (gender) dan Pengalaman (experience). Berdasarkan pengujian melalui bootstrapping pada aplikasi SmartPLS, maka hasil pengujian terlihat pada Tabel 5 dan Tabel.

Tabel 5. Uji efek moderasi gender

\begin{tabular}{cccc}
\hline Hipotesis & Hubungan & t-value & Keputusan \\
\hline H1 & AT * GEN $\rightarrow$ CUI & 0.1907 & Ditolak \\
H3 & PEOU * GEN $\rightarrow$ PU & 0.881 & Ditolak \\
H4 & PU * GEN $\rightarrow$ AT & 0.067 & Ditolak \\
\hline
\end{tabular}

Tabel 6. Uji efek moderasi experience

\begin{tabular}{cccc}
\hline Hipotesis & Hubungan & t-value & Keputusan \\
\hline $\mathrm{H} 1$ & $\mathrm{AT}^{*}$ EXP $\rightarrow$ CUI & 0.3964 & Ditolak \\
$\mathrm{H} 3$ & $\mathrm{PEOU}^{*}$ EXP $\rightarrow$ PU & 0.449 & Ditolak \\
$\mathrm{H} 4$ & $\mathrm{PU}^{*}$ EXP $\rightarrow$ AT & 0.67 & Ditolak \\
\hline
\end{tabular}

Pada Tabel 5 dan Tabel 6 di atas terlihat bahwa semua hipotesis ternyata ditolak dalam uji efek moderasi pada penelitian ini. Hal ini berarti tidak ada perbedaan antara jenis kelamin dan pengalaman dalam penggunaan tekologi awan.

Berdasar analisis yang telah dilakukan, maka penelitian ini bisa menghasilkan sebuah model penelitian baru yang sesuai dengan studi kasus yang diambil. Model penelitian baru ini bisa dilihat pada Gambar 2.

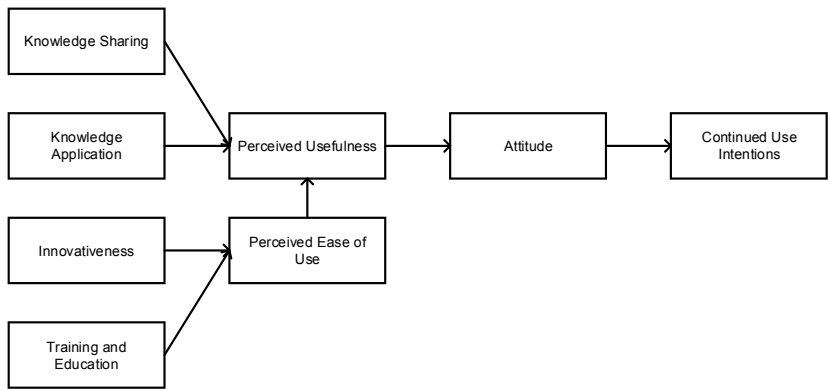

Gambar 2. Model Penelitian Baru

\section{SIMPULAN}

Hasil analisis yang telah dilakukan oleh peneliti akhirnya bisa diambil sebuah kesimpulan terhadap penelitian yang telah dilakukan. Pada subyek 
penelitian yang merupakan mahasiswa jurusan Sistem Informasi di Jakarta Selatan, sebagian besar penggunaan teknologi penyimpanan awan ternyata dipengaruhi oleh sikap dalam menggunakan teknologi tersebut. Hubungan kedua konstruk ini merupakan yang terkuat dalam penelitian ini. Sementara persepsi kegunaan dan kemudahan penggunaan ternyata berpengaruh besar terhadap sikap dari pengguna teknologi penyimpanan awan.

Persepsi dari kegunaan penggunaan penyimpanan digital dipengaruhi oleh bagaimana pengetahuan dikelola (knowledge management) dan kemudahan penggunaan itu sendiri dipengaruhi oleh tingkat inovasi dari mahasiswa dan bagaimana mereka mendapatkan pendidikan atau pelatihan mengenai cara penggunaan teknologi penyimpanan awan. Sementara apabila dilihat pada pengaruh moderasi jenis kelamin dan pengalaman, ternyata tidak ada perbedaan terhadap semua mahasiswa. Baik mahasiswa pria dan wanita, semua faktor yang mempengaruhi penggunaan teknologi komputasi awan adalah serupa. Hal yang sama juga terjadi pada bila dilihat pada sisi pengalaman penggunaan teknologi ini.

\section{DAFTAR RUJUKAN}

[1] I. Arpaci, "Antecedents and consequences of cloud computing adoption in education to achieve knowledge management," Computers in Human Behavior, pp. 382-390, 2017

[2] Kanhalli, "A Model of Organizational Knowledge Management Maturity based on People, Process, and technology," Forthcoming in Journal of Information \& Knowledge Management, Vol. 8 pp. 1-21. 2009.
[3] I. Nonaka, "A Dynamic Theory of Organizational Knowledge Creation," Organization Science, pp. 1437, 1994.

[4] A. Goscinski, J. Broberg \& R. Buyya, Cloud Computing: Principles and Paradigms, New Jersey: John Wiley \& Sons, pp. 137. 2011.

[5] F. D. Davis, "Perceived usefulness, perceived ease of use, and user acceptance of information technology," MIS Quarterly, vol. 13, no. 3, pp. 319-339, 1989.

[6] J. F. Hair, G. T. M. Hult, C. Ringle \& M. Sarstedt, A Primer on Partial Least Squares Structural Equation Modeling (PLS-SEM), 1st Edition ed., California: Sage Publications, Inc, pp. 216. 2014.

[7] C. E. Werts, R. L. Linn \& K. G. Joreskog, "Interclass reliability estimates: Testing structural assumptions," Education and Psychological Measurement, vol. 34, no. 1, pp. 25-33, 1974.

[8] J. F. Hair, W. C. Black \& B. J. Babin, Multivariate Data Analysis: A Global Perspective, New Jersey: Pearson Education, pp. 216. 2010.

[9] C. Fornell \& D. F. Larcker, "Evaluating structural equation models with unobservable," Journal of Marketing Research, vol. 1, no. 18, pp. 39-50, 1981.

[10] J. C. Nunnally \& I. H. Bernstein, "Psychometric theory,” PsycCRITIQUES, Elsevier, pp. 275-280, 1979.

[11] K. G. Jöreskog, “A general approach to confirmatory maximum likelihood factor analysis," Psychometrika, Vol. 34, No. 2, p. 183-202, 1969. 